\title{
Orofacial Pain: Guidelines for Assessment, Diagnosis, and Management
}

\author{
Reny de Leeuw, Gary D. Klasser (editors) \\ Publisher: Quitessence Publishing Co Inc \\ Language: English \\ ISBN: 978-0-86715-610-2 \\ Edition: $5 / \mathrm{e}$ \\ Publish Year: 2013 \\ Pages: 312, illustrated \\ Price: $\$ 48.00$
}

The American Academy of Orofacial Pain (AAOP), an organization of health care professionals who promote education, research and patient care in the field of orofacial pain and associated disorders has published a new edition of the Orofacial Pain Guidelines edited by Reny de Leeuw and Gary Klasser.

This book is a must for every practitioner interested in the assessment, diagnosis and management of orofacial pain and associated conditions.

This edition includes 12 chapters, which start with a series of key points to help direct the reader. After presenting the anatomical and neurophysiological considerations on orofacial pain and the comorbid conditions in chapter 1 follows a comprehensive evaluation of patients in order to establish the diagnosis.

Classification systems and differential diagnosis of orofacial pain are developed in the 3rd chapter. Vascular and nonvascular intracranial disorders and primary headache disorders are discussed in the next two chapters.

Chapter six details episodic and continous neuropathic pain. Odontogenic, nonodontogenic and oral mucosal pain is discussed in chapter seven named intraoral pain disorders.

The anatomy of the masticatory structures, defining, epidemiology, etiology, diagnostic classification and management of TMDs s are amply developed in the next chapter. The cervical spine structures are in close correlation with the temporomandibular
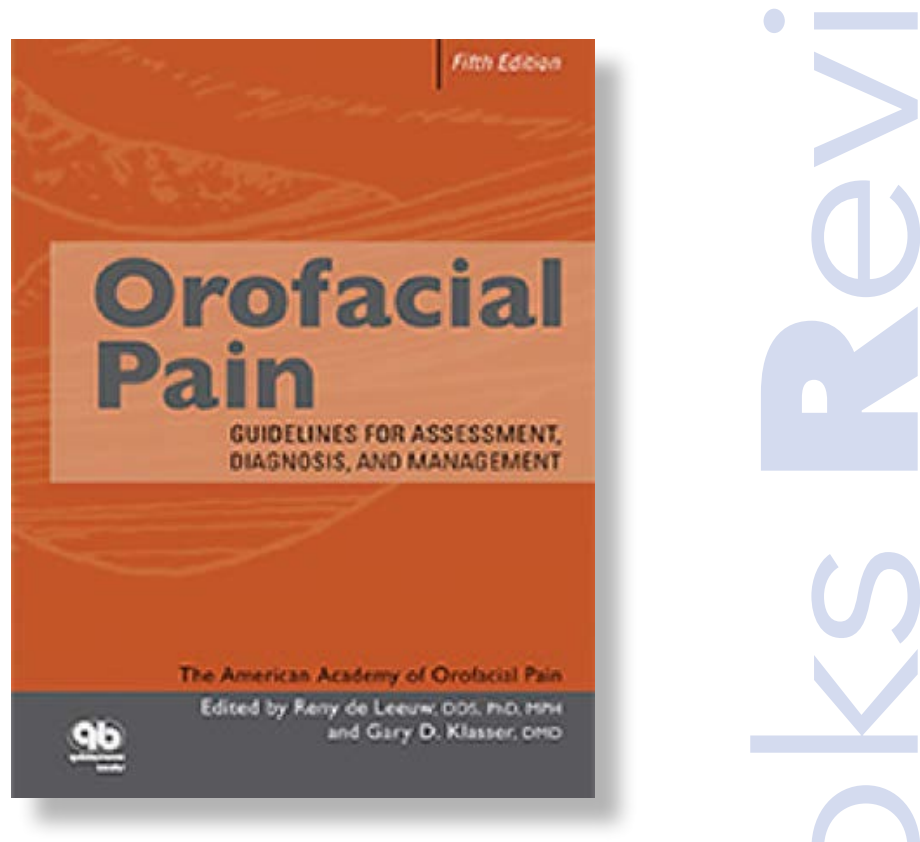

joint and has an important role in the cevicogenic mechanisms of orofacial pain. These are topics largely developed in chapter nine.

Pain stemming from tissues or organs in the head and neck and systemic disease are presented in the next chapter: extracranial causes of orofacial pain and headaches. An entirely new chapter is included and talks about sleep and its relationship to orofacial pain and well-being.

The final chapter of the book tackles the comprehensive evaluation of the bio-behavioural factors in orofacial pain implementing a dual-axis coding (RDC/TMD Axis II).

Numerous AAOP members and nonmembers that contribute to the fifth edition of the AAOP Guidelines have had a substantial contribution to a complete textbook on all aspects of oral facial pain in order to facilitate communication among clinicians, researchers, academics, and patients.

https://doi.org/10.25241/stomaeduj.2015.2(2).bookreview.6

The Book Review is drafted in the reviwer's sole wording and illustrates his opinions.

Marian-Vladimir Constantinescu DDS, PhD Department of Prosthetic Dentistry "Carol Davila" University of Medicine and Pharmagy Bucharest, Romania Email: dr.vadimir.constantinescu@gmail.con 